\title{
A Chronic-Low-Dose Exposing of DEHP with OECD TG 443 Altered the Histological Characteristics and Steroidogeic Gene Expression of Adrenal Gland in Female Mice
}

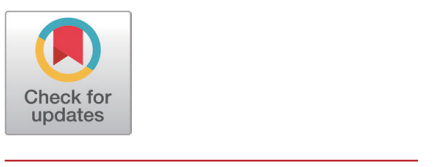

* These authors contributed equally to this work.

Received: August 30, 2021

Revised: November 13, 2021

Accepted: December 4, 2021

${ }^{+}$Corresponding author

Yong-Pil Cheon

Division of Developmental Biology and

Physiology, Department of Biotechnology,

Institute of Basic Sciences, Sungshin

University, Seoul 02844, Korea.

Tel: +82-2-920-7639

Fax: +82-2-920-2736

E-mail:ypcheon@sungshin.ac.kr

Copyright $\odot 2021$ The Korean Society of Developmental Biology.

This is an Open Access article distributed under the terms of the Creative Commons Attribution Non-Commercial License (http://creativecommons.org/licenses/ by-nc/4.0/) which permits unrestricted non-commercial use, distribution, and reproduction in any medium, provided the original work is properly cited.

ORCID

Bo Young Lee

https://orcid.org/0000-0001-9178-8099 Jeong Bin Jo

https://orcid.org/0000-0001-9622-8322 Donchan Choi

https://orcid.org/0000-0002-5170-090X

Sung-Ho Lee

https://orcid.org/0000-0003-2866-3642

Yong-Pil Cheon

https://orcid.org/0000-0002-8497-9257
Bo Young Lee ${ }^{1, *}$, Jeong Bin Jo ${ }^{1, *}$, Donchan Choi ${ }^{2}$, Sung-Ho Lee ${ }^{3}$, and ${ }^{\dagger}$ Yong-Pil Cheon'

'Division of Developmental Biology and Physiology, Center for Development and Program Research, Department of Biotechnology, Institute of Basic Sciences, Sungshin University, Seoul 02844, Korea

${ }^{2}$ Dept. of Life Science, College of Environmental Sciences, Yong-In University, Yongin 17092, Korea

${ }^{3}$ Dept. of Biotechnology, Sangmyung University, Seoul 03016, Korea

\section{Abstract}

Phthalates and their metabolites are well-known endocrine disrupting chemicals. Di-(2ethylhexyl) phthalate (DEHP) has been widely used in industry and the exposing possibility to adult is high. In this study, DEHP was treated (133 $\mu \mathrm{g} / \mathrm{L}$ and $1,330 \mu \mathrm{g} / \mathrm{L}$ in drinking water) according to the OECD test guideline 443 to mature female mice and their adrenal gland were examined for histological characteristics and steroidogenic gene expression. The wet weight of the adrenal gland was increased in all administrated groups compared to control. The diameter of zona fasciculata (ZF) was increased by DEHP in both outer ZF and inner ZF but there was no difference in morphology of the cells and arrangements into zona between groups. In addition, the arrangement of extracellular matrix was not different between control and DEHP groups. CYP11B1 was mainly localized at ZF and the intensity was not different between groups. DAX1 was localized in zona glomerulosa (ZG) and ZF, and its expression levels were decreased by DEHP administration. Its level was lower in DEHP133 group than DEHP1330 group. On the other hand, CYP17A1 was localized in ZG of DEHP1330 group. These results suggest that chronic low-dose DEHP exposing may modify the microstructure and function of the adrenal cortical cortex.

Keywords: Di-(2-ethylhexyl) phthalate, Adrenal gland, CYP11B1, CYP17A1, DAX1, Endocrine disrupting chemical

\section{INTRODUCTION}

$\mathrm{Di}(2$-ethylhexyl) phthalate (bis(2-ethylhexyl) phthalate, also known as diethylhexyl phthalate, Di(2-ethylhexyl) phthalate (DEHP), dioctyl phthalate, DOP, Octyl phthalate; di-sec octyl phthalate) is the lead substance of phthalate esters, because DEHP has been widely used as a plasticizer in flexible 
Conflict of interests

The authors declare no potential conflict of interest.

\section{Acknowledgements}

This works was supported by a grant of National Research Foundation of Korea (2021K1A4A7A02098794).

\section{Authors' contributions}

Conceptualization: Cheon YP.

Data curation: Lee BY, Jo JB.

Formal analysis: Lee BY, Jo JB, Cheon YP.

Methodology: Lee BY, Jo JB.

Validation: Choi D, Lee SH, Cheon YP.

Investigation: Lee BY, Jo JB, Cheon YP.

Writing-original draft: Cheon YP.

Writing-review \& editing: Choi D, Lee $\mathrm{SH}_{\text {, }}$ Cheon YP.

\section{Ethics approval}

All animal experiments were conducted in accordance with the Guide for the Care and Use of Laboratory Animals published by the National Institute of Health. vinyl products and largely produced among them. It is ubiquitously detected from environmental samples and organisms are easily exposed to it (Ito et al., 2019). In human, about half of DEHP is excreted as mono(2-ethylhexyl) phthalate (MEHP) (7.34\%), 5-OH-MEHP (24.7\%), and 5-oxoMEHP (14.9\%) within 2 days and the estimated serum elimination half-life of these metabolites is less than $2 \mathrm{~h}$ (Koch et al., 2004). Generally, the effects of phthalates are due to the monoester and metabolites derived therefrom. By the adverse effects of DEHP, in the United States and Canada, it is no longer used to manufacture for children's products intended for mouthing. In the other countries also have been restriction of their usage through law. However, by its high product volume and common use, DEHP leach into the environment over time.

Phthalates were classified as endocrine disrupting chemicals (EDCs) in 2002 and DEHP has antiandrogen and estrogenic activities (Chen et al., 2014). By the in utero exposing of DEHP (100$900 \mathrm{mg} / \mathrm{kg} / \mathrm{d}$ from gestational d14-19 in rat), a reduced androgen production is induced and this is coincident with reduced mineralocorticoid receptor (MR) expression in Leydig cells with epigenic change in MR gene promoter at postnatal day 60 (Martinez-Arguelles et al., 2009). In estrogen receptor 1 (ER1) cell line, it shows a high agonistic and antagonistic activity, but a low agonist activity and a high antagonist activity in MVV-Luc cell line (Simon et al., 2016). It also suggested that DEHP induces the transactivation of ER (Chen et al., 2014). On the other hand, the risks of DEHP in carcinogenesis and child health has been focused with peroxisome proliferator-activated receptors (PPARs), because the metabolites of DEHP work as ligand of PPARs (Maloney \& Waxman, 1999). It is classified as a potential carcinogen by the International Agency for Research on Cancer and the European.

Initial reproductive and developmental toxicity studies on phthalates did in pregnant female rodent and fetus. It showed various toxicity in implantation, reabsorptions, decreased body weight, and increased malformations in dose and developmental stage dependent manners (Tyl et al., 1988; Cheon, 2020). The well examined target organs of DEHP include ovary (Komar et al., 2001), testis (Li et al., 2014), endometrium, placenta, liver (Lovekamp-Swan \& Davis, 2003), placenta (Martínez-Razo et al., 2021), renal, lung, immune system, brain development, and heart tissue (Martínez-Razo et al., 2021).

The absorption and metabolism of DEHP vary in vivo female by various factors such as species, physiological status. DEHP in CD-1 mice and Wistar rat is rapidly absorbed and reached to peak plasma levels with linearity with the absorption and a rapid increase is noted in mice but not in rats. The plasma half-life times ranged between 7.1 and $10.3 \mathrm{~h}$ at the low dose and between 5.5 and $13.5 \mathrm{~h}$ at the high dose. MEHP is dominant in blood both at the low and the high dose level. MEHP metabolites in blood are detected in rat but not in mouse. Repeated DEHP administration modify the metabolic pathway and decrease of DEPH excretion and increase of MEHP excretion in pregnant mice (Lorz et al., 2012). In marmosets, the organ/plasma ratio is generally 0.2 to 0.4 and does not alter the distribution by pretreatment for 65 weeks (Zeiger et al., 1985).

Even though the usage of DEHP in industry is strictly regulated and the environment is tried to control, huge amount of industrial products had been around for a long time already. Therefore, it could be chronically exposed with low concentration through air, water, soil, and food (United States Environmental Protection Agency, 2013). Recently, there are many scientists suggest that low dose phthalate impacts on health of animals such as fertility and steroidogenesis (Bloom et al., 2015) and become a big issue in this field (Vandenberg et al., 2019). As the previous results, the possibility of chronic exposures to low-dose DEHP is an effect as EDC in the uterus without effect on F1 fertility (Cha et al., 2017; Cheon, 2020). Chronic low dose exposure of DEHP caused increase the uterine wet weight, endometrial thickness, and the number of glands (Cheon, 2020). Besides, it caused decreased expression of estrogen receptors in uterus. From such results, it is 
suspected that the adrenal gland can be a target organ of low level of DEHP.

DEHP induces various effects on various cellular responses including modulation of transcriptome such as steroid hormone receptors and paracrine factors. It is suggested that DEHP cause of cancer, reproductive, developmental, and immune toxicities, and endocrine disruption effects. Its effects have been studied on reproductive organs, kidney, lung, immune system, and nervous system. Although the adrenal gland is a suspected target endocrine organ of DEHP and important for development, only limited information is available about the effect of DEHP. In this study, the histological changes and the expression profiles of steroidogenic genes were evaluated in chromic low dose DEHP exposed adult female mice.

\section{MATERIALS AND METHODS}

\section{Experimental animal}

All animal experiments were conducted in accordance with the Guide for the Care and Use of Laboratory Animals published by the National Institute of Health. CD-1 (ICR) mice were maintained under standard condition at the animal house of Sungshin University. Circadian rhythm was kept under the 14L:10D schedule with light-on at 06:00 and clean room system. Animals were fed food and drink as mentioned in Cha et al. (2017). In brief, estrogen-free rodent diet (2018 Teklad global 18\% protein rodent diets; ENVIGA, Madison, WI, USA) and water in glass bottles with stainless steel sipper tubes were offered ad libitum.

\section{Di-(2-ethylhexyl) phthalate (DEHP) treatment and adrenal gland sampling}

Administration of DEHP (Catalog no. 36735, Sigma Aldrich, St. Louis, MO, USA) was followed OECD Guidelines for the Testing of Chemicals - Test Guideline No. 443. Ten to twelve-week-old animals were given DEHP at a dose of 133 or 1,330 $\mu \mathrm{g} / \mathrm{L}$ (DEHP133 and DEHP1330, respectively) dissolved in drinking water for 10 weeks, considering that a mouse drinks approximately 4-7 mL of water daily. Control group was given water without test substances. Estrous cycle was checked by vaginal smearing daily for first 2 weeks, then each normal cycling female was chosen and bred with a fertile male for 2 weeks (n=10/each group). Copulatory plug was checked daily. After 6 weeks, animals were used for examination. The animal body weight was measured and then sacrificed. The adrenal glands were dissected and measured wet weight of them.

\section{Histology}

After measuring the weight, they were fixed with $4 \%$ buffered paraformaldehyde in PBS and routinely embedded in paraffin. The paraffin-embedded adrenal glands were serial sectioned (coronal section) at $4 \mu \mathrm{m}$ and mounted on glass slides. Every tenth sections of an adrenal gland were chosen, deparaffinized with xylene, and hydrated with alcohol series. And they were stained by Hematoxylin-Eosin. To evaluate the possible changes of extracellular matrix (ECM), Masson trichrome staining was used. The stained tissues were observed under the light microscope (Nikon, Japan). For image analysis the freeware ImageJ (National Institutes of Health software) v1.33 and the Color Histogram plug-in, both downloaded from the NIH website (http://rsb.info.nih.gov/ij) were used as mentioned in previous report (Kim et al., 2015).

\section{Immunohistochemical analysis}

Endogenous peroxidase activity was blocked with $0.3 \%$ hydrogen peroxide in $\mathrm{H}_{2} \mathrm{O}$ for $30 \mathrm{~min}$. CYP11B1, CYP17A1, and DAX1 was localized according to the Vectastain ABC kit method 
(Vector Laboratories, Burlingame, CA, USA). Briefly, tissues were incubated with 1\% normal blocking serum in PBS for 20 min and then incubated with CYP11B1 antibody (dilution 1:500, polyclonal antibody, Cat No: MBS2026360, MyBioSource com), CYP17A1 antibody (dilution 1:100, monoclonal antibody, Cat No: sc-374244, Santa Cruz Biotechnology), and NR0B1(DAX1, dilution 1:100, polyclonal antibody, MyBioSource com). After washed in PBS containing 0.1\% triton X-100 (PBST) and PBS, tissues were incubated with anti-mouse IgG (Vector Laboratories). Tissues were washed and incubated with avidin-biotin-complex reagent containing horseradish peroxidase for $30 \mathrm{~min}$. Tissues were washed and color development was achieved using DAB substrate. The tissues were counterstained with hematoxylin.

\section{Statistical analysis}

These studies were done with repeated measurements (10 animals/group). The data were presented as mean \pm SED and analyzed using SAS. One-way ANOVA was used to evaluate statistical difference, followed by $t$-test was performed for comparisons of two means. $p$-values $<0.05$ were considered significant.

\section{RESULTS}

\section{Weight gain in prolonged exposure of di-(2-ethylhexyl) phthalate (DEHP)}

After drinking for 10 weeks, the mice were sacrificed and measure the wet weight as mentioned in Materials and Methods. The wet weight of adrenal glands was significantly increased in both $133 \mu \mathrm{g} / \mathrm{L}(p<0.05)$ and $1,330 \mu \mathrm{g} / \mathrm{L}(p<0.05)$ groups (Fig. 1A). The relative weight also significantly heavy in both $(p<0.05)$ groups $(0.0001,0.0002$, and 0.0002 in control, DEHP133, and DEHP1330, respectively) (Fig. 1B).

\section{Histological changes and immunohistochemical analysis of steroidogenic enzymes in adrenal gland}

There was no histological change in cell shapes or grouping (Fig. 2) but the diameter of zona

A

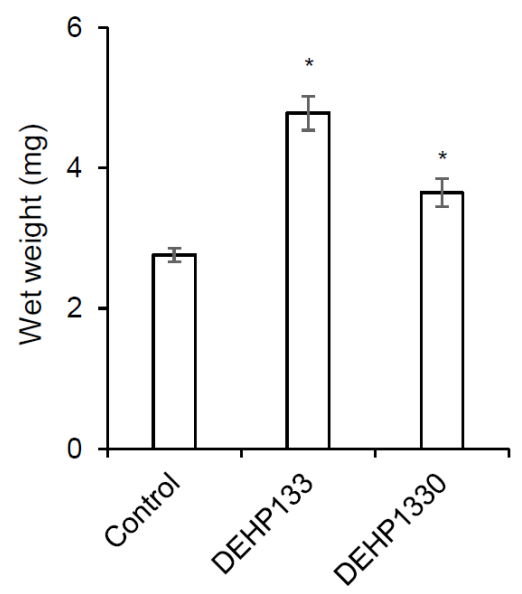

B

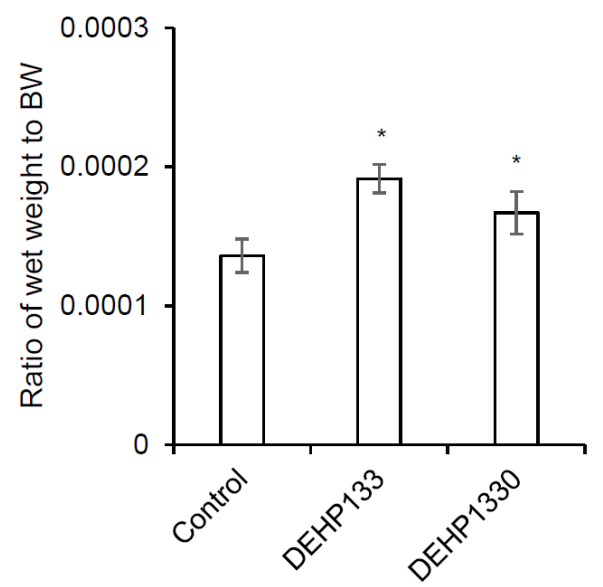

Fig. 1. Change of the weight of maternal adrenal gland. (A) Wet weight of adrenal gland. (B) Ration of wet weight to body weight. The female mice were administered DEHP with drink for 10 weeks according to the OECD test guideline 443. The weight of adrenal gland was measured after sacrifice. ${ }^{*} p<0.05$ (ANOVA and $t$-test, control vs DEHPs). DEHP, di-(2-ethylhexyl) phthalate. 
was not same between groups. The thickness of capsule was not different between groups (Fig. $3 \mathrm{~A})$. The diameter of zona glomerulosa (ZG) was decreased by DEHP and there was significantly difference $(p<0.05)$ in DEHP133 group (Fig. 3B). However, the diameter of zona fasciculata (ZF) was increased by DEHP in both DEHP133 and DEHP1330 (Fig. 3C). The ZF can be distinguished likes outer ZF (oZF) and inner ZF (iZF). Comparing the diameter of oZF and iZF, it was increased significantly $(p<0.05)$ in DEHP groups. the case of $Z R$, the diameters were significantly increased in both DEHP133 and DEHP 1330 groups in the concentration dependent manners (Fig. 3D, 3E).

For the next step, the stability of the ECM was examined with the trichrome staining tool. The patterns of ECM deposit were not different between groups (Fig. 4). In the adrenal gland, collagen was strongly deposited in cortex and the border of medulla and cortex. It also localized between the cords.

The expression of steroidogenic enzymes was evaluated with IHC. CYP17A1 is not expressed at adrenal cortex in laboratory mice in physiological status. Its expression was not detected in control and DEPH133 groups (Fig. 5A, 5B). In DEHP1330 group, the CYP17A1 specific staining was detected in ZG cells (Fig. 5C).

Cytochrome P45011B1 (11 $\beta$-hydroxylase) respond for production of cortisol/corticosterone in adrenal cortex. It was predominantly localized in oZF and lesser in iZF. The staining intensity of it was not different between groups (Fig. 6A-6D). It means that the chronic low-dose DEHP administration did not affect on the expression of CYP11A1 in maternal mice.

DAX1 is a nuclear receptor and has function as a regulator of steroidogenic enzyme induction and differentiation of adrenocortical cell. Its intensity was significantly decreased $(p<0.05)$ in both DEHP133 and DEHP1330. The inhibitory effect of DEHP was stronger in DEHP133 group

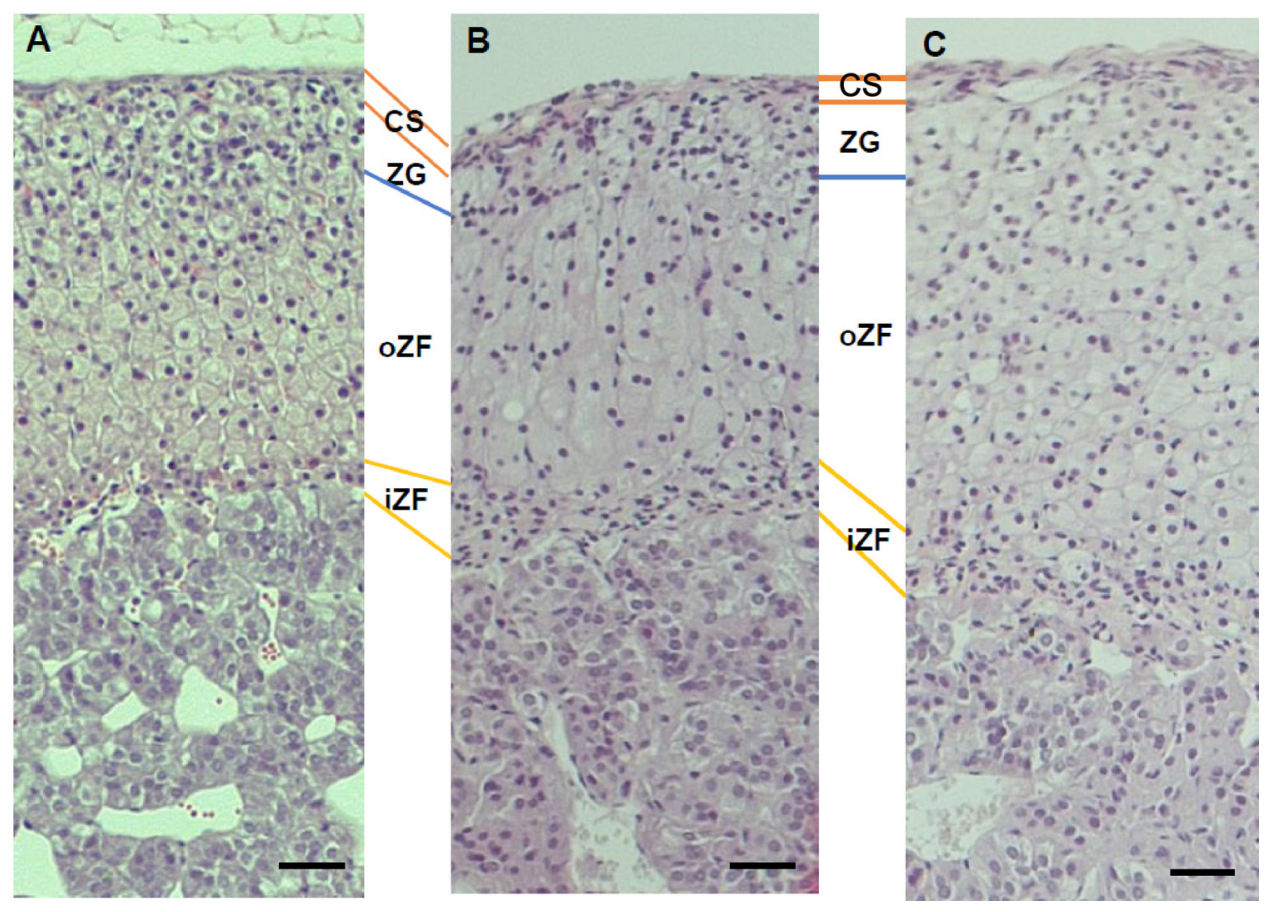

Fig. 2. Micrography of adrenal gland in chronic low-dose DEHP administered maternal mice. (A) Control; (B) $133 \mu \mathrm{g} / \mathrm{L}$ DEHP in drinking water for 10 weeks; (C) 1,330 $\mathrm{gg} / \mathrm{L}$ DEHP in drinking water for 10 weeks. $\mathrm{H}$-E staining (scale bar = $100 \mu \mathrm{m}$ ). CS, capsule; ZG, zona glomerulosa; oZF, outer zona fasciculata; iZF, inner zona fasciculata; DEHP, di-(2-ethylhexyl) phthalate. 
A

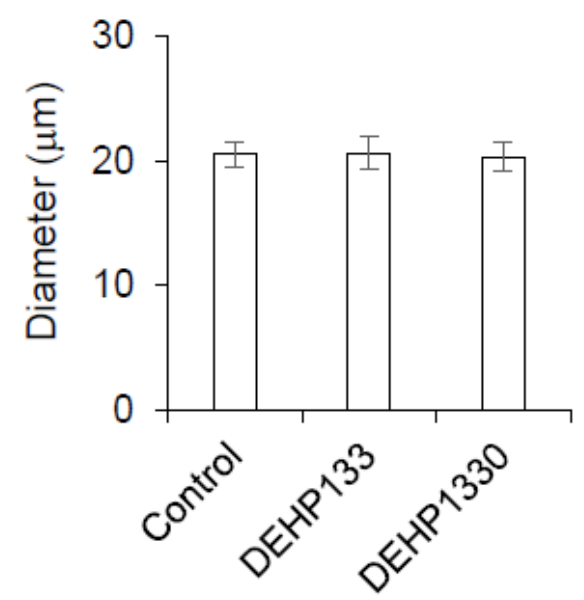

$\mathrm{B}$

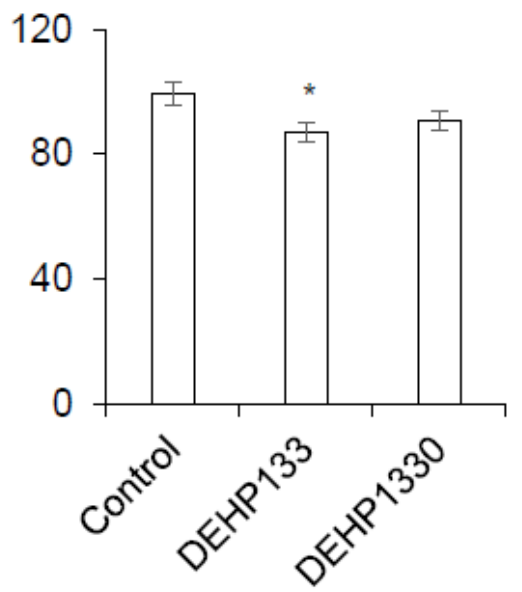

C

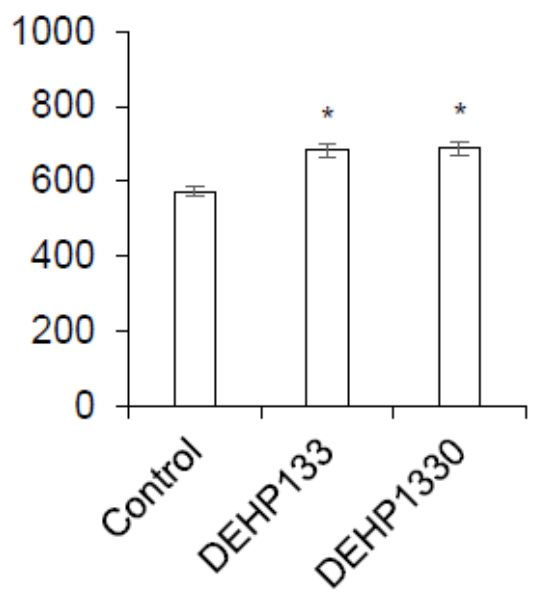

D

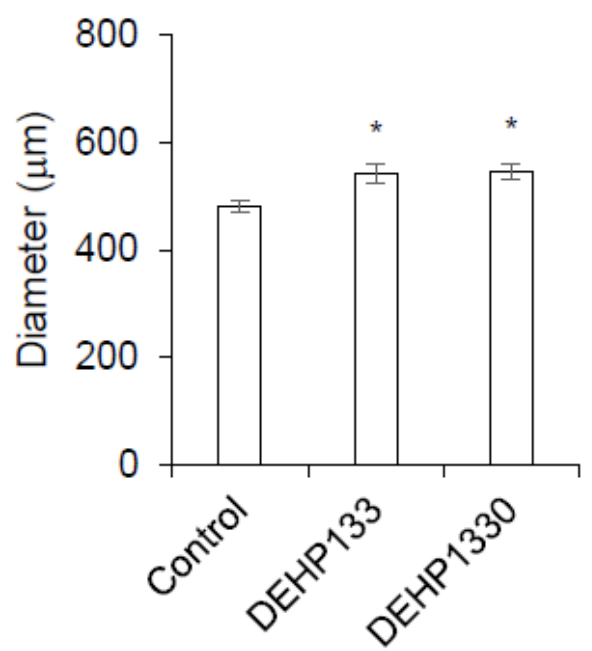

$\mathrm{E}$

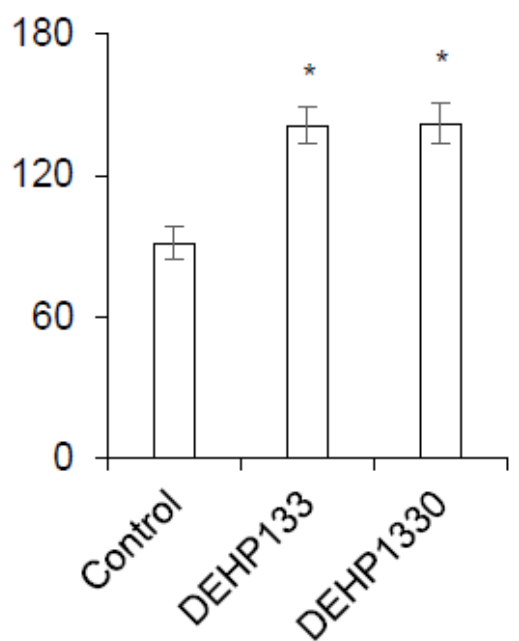

Fig. 3. The thickness of the zonas of adrenal cortex. Coronal sections were used to measure the thickness. (A) Capsules; (B) zona glomerulosa; (C) zona fasciculata; (D) outer zona fasciculata; (E) inner zona fasciculata. * $p<0.05$ (ANOVA and $t$-test, control vs DEHPs). DEHP, di-(2-ethylhexyl) phthalate.
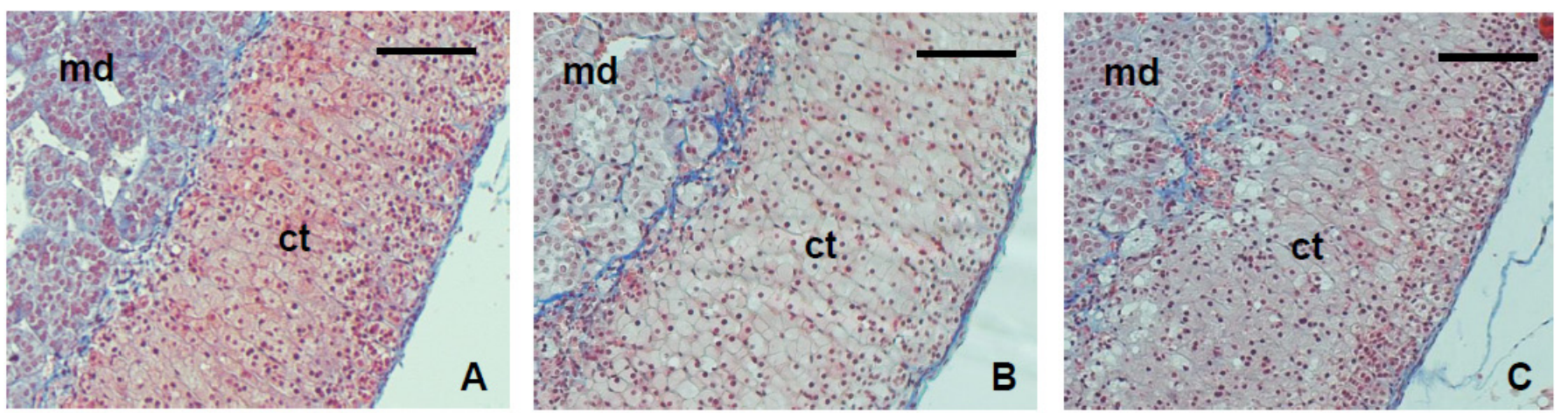

Fig. 4. Micrography of the adrenal gland in chronic low-dose DEHP administered maternal mice. The blue color showed the ECM molecule, collagen. The sections were stained with trichrome staining (scale bar = $100 \mu \mathrm{m})$. md, medulla; ct, cortex; DEHP, di-(2-ethylhexyl) phthalate; ECM, extracellular matrix. 

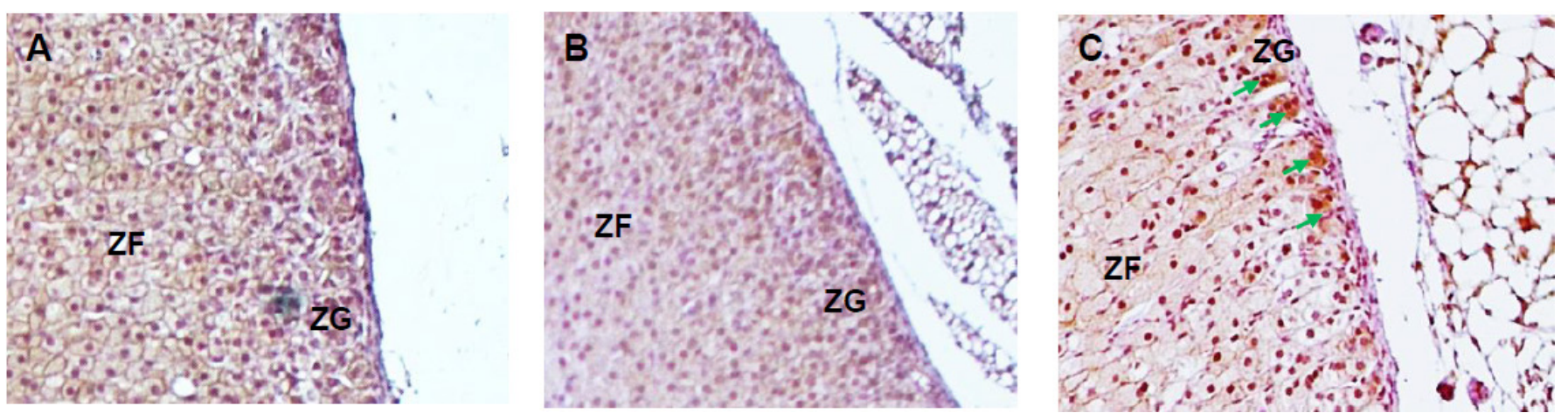

Fig. 5. Immunohistochemistry of CYP17A1 in adrenal gland. Arrow is the glomerular structure stained specifically with CYP17A1 antibody. (A) Control; (B) $133 \mu \mathrm{g} / \mathrm{L}$ DEHP in drinking water for 10 weeks; (C) 1,330 $\mu \mathrm{g} / \mathrm{L}$ DEHP in drinking water for 10 weeks. ZG, zona glomerulosa; ZF, zona fasciculate; DEHP, di-(2-ethylhexyl) phthalate.
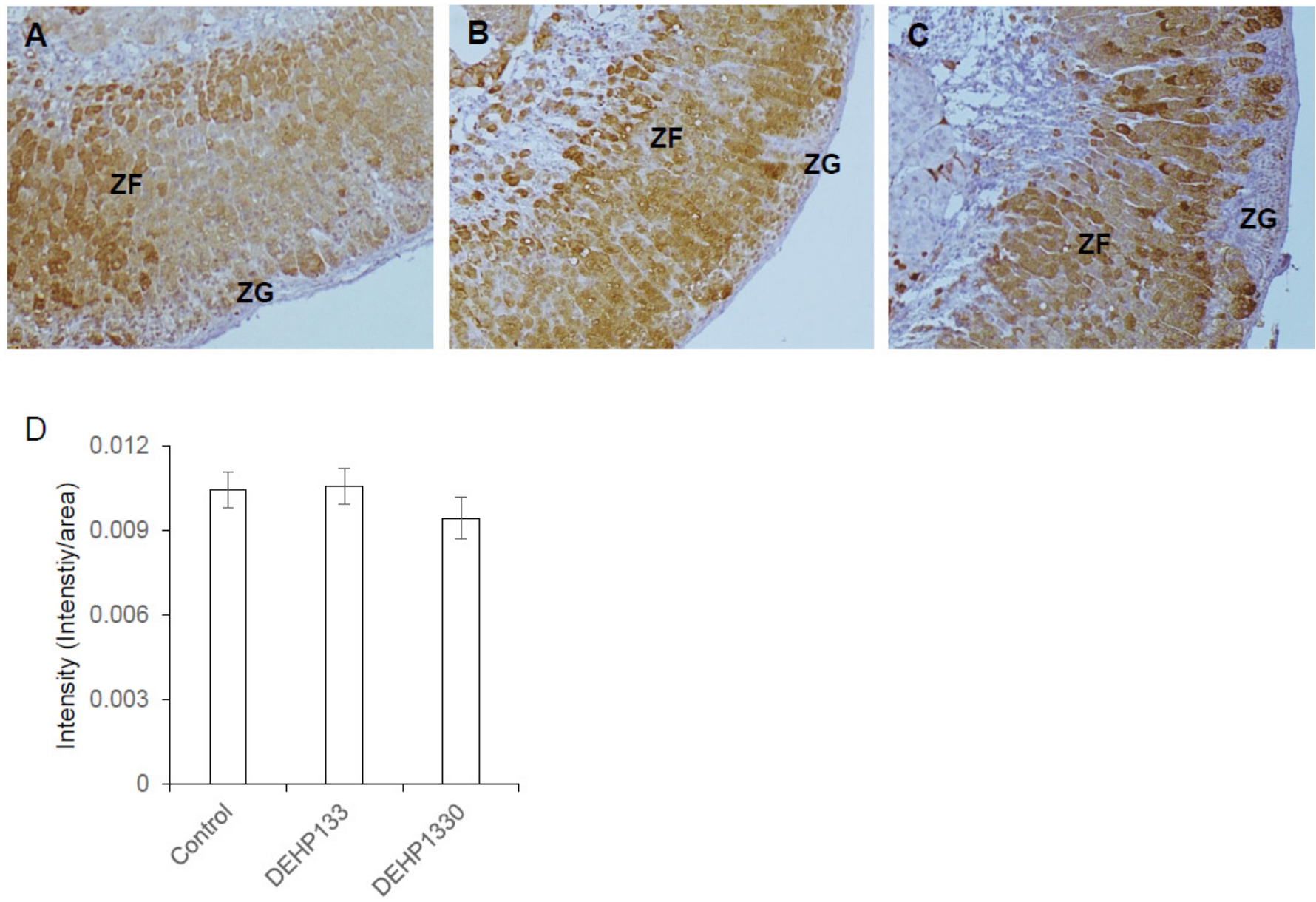

Fig. 6. Immunohistochemistry of CYP11B1 in adrenal gland. CYP11B1 was dominantly stained at ZF. (A) Control; (B) $133 \mu \mathrm{g} / \mathrm{L}$ DEHP in drinking water for 10 weeks; (C) 1,330 $\mathrm{\mu g} / \mathrm{L}$ DEHP in drinking water for 10 weeks; (D) intensity per area of CYP11A1 specific staining. ZG, zona glomerulosa; ZF, zona fasciculate; DEHP, di-(2-ethylhexyl) phthalate.

than DEHP1330 group (Fig. 7A-7D). In control mice, DAX1 was localized in nucleus of ZG and ZFs (Fig. 7A). In DEHP133 group, DAX1 was localized more strongly in the nucleus of ZG compared to ZFs (Fig. 7B). The nuclear localization of DAX1 in DEHP1330 group was similar 

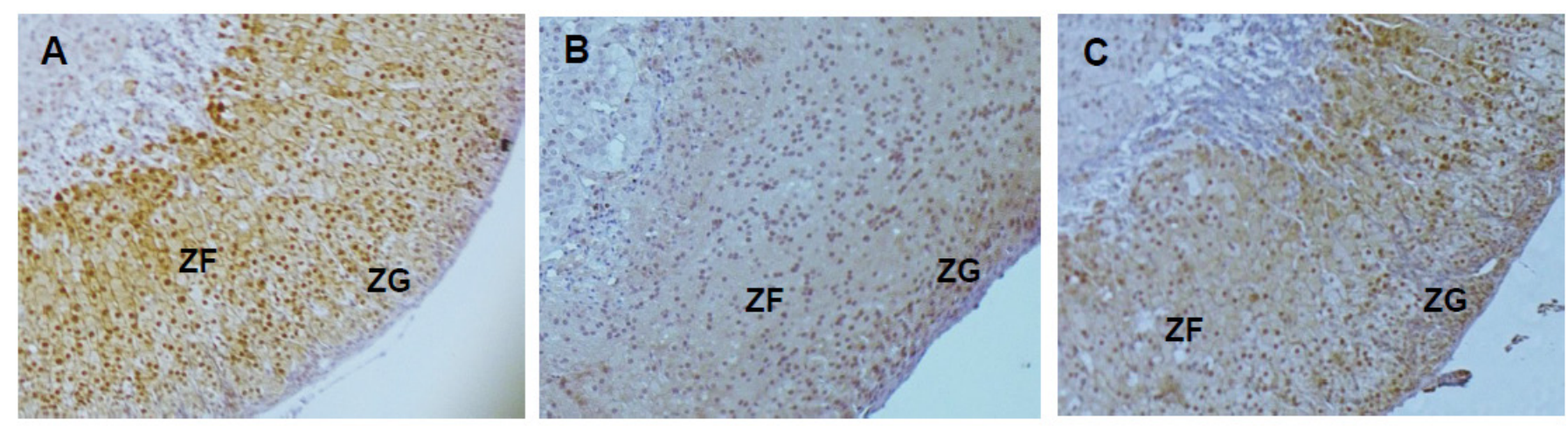

D

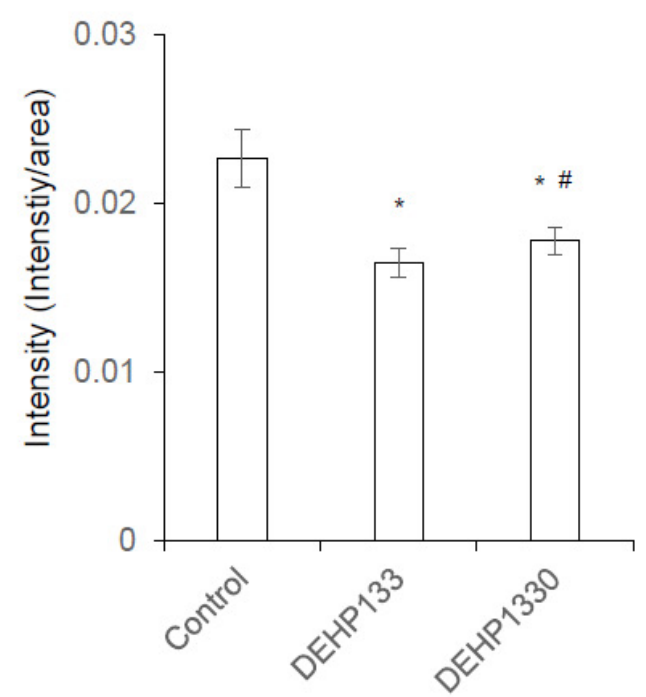

Fig. 7. Immunohistochemistry of DAX1 in adrenal gland. DAX1 was stained all zonas. Its expression levels were decreased in DEHP groups. (A) control; (B) $133 \mu \mathrm{g} / \mathrm{L}$ DEHP in drinking water for 10 weeks; (C) 1,330 $\mu \mathrm{g} / \mathrm{L}$ DEHP in drinking water for 10 weeks; (D) intensity per area of DAX1 specific staining. ${ }^{*} p<0.05$ (ANOVA and $t$-test, control vs DEHPs). \# $p<0.05$ (t-test, DEHP133 vs DEHP1330). ZG, zona glomerulosa; ZF, zona fasciculate; DEHP, di-(2ethylhexyl) phthalate.

with control group and localized in ZG and ZFs but weaker than that of the control (Fig. 7C).

\section{DISCUSSION}

OECD test guideline 443 provides a detailed description of the operational conduct of an extended one generation reproductive toxicity study and may be extended to include an F2 generation. In this study, the maternal female drunk for 10 weeks containing DEHP were evaluated. The adverse effects of DEHP in reproductive organs and development has been evaluated, and revealed the involvement of PPAR-dependent pathways in DEPH toxic effects. DEHP acts on the liver lipid metabolism and increases enzyme activities involved in mitochondrial and peroxisomal fatty acid $\beta$ - and $\omega$-oxidation through PPARs in species-specific manners. Low dose DEHP $(1 \mathrm{mg} / \mathrm{kg} /$ day) exposing at uterus led DNA methylation changes at doses below those that affect aldosterone biosynthesis with decreased PPAR $\alpha$ expression (Martinez-Arguelles \& Papadopoulos, 
2015). On the other hand, during adult exposing of DEHP effects on steroidogenesis pathway of various target organs (Ahmad et al., 2022). CYP11B1 is the classical $11 \beta$-hydroxylase which converts 11-deoxycortisol to cortisol and deoxycorticosterone to corticosterone. Cyp11b1 null cause of glucocorticoid deficiency, mineralocorticoid excess, and congenital adrenal hyperplasia (Zhang et al., 2020). Glucocorticoid secretion relies on the CYP11B1 and production is mainly under the control of the hypothalamo-pituitary-adrenal axis and ACTH/cAMP/PKA signaling (Dumontet \& Martinez, 2021). An orphan nuclear receptor, DAX1 (NR0B1) is important in function of the adrenal gland. It is localized in subcapsular area and its expression is activated by glucocorticoids and inhibited by ACTH (Gummow et al., 2006; Kim et al., 2008). One of the roles of Dax1 is the maintenance of subcapsular adrenocortical progenitor cells (Scheys et al., 2011) and the hormonally induced changes in SF-1/DAX1 ratio cause the fine tune ACTH responsiveness of ZF cells (Ragazzon et al., 2006).

The adrenal cortex is a unique morphological and functional zonation consisted with three cell types. These cells are developed from the mesenchymal tissue adjacent to the coelomic epithelium near the urogenital ridge and an additional cell type originated from the mesonephros and the region of Bowman's capsule (McCabe et al., 2001). The adrenal cortex is clearly subdivided into $\mathrm{ZG}, \mathrm{ZF}$, and $\mathrm{ZR}$ in human and some primates by cellular arrangements. $\mathrm{ZR}$ is considered unique to humans and certain primates (Turcu et al. 2018). In the case of the adult female Prkar1a AdKO, adrenal cortex can be classified as ZG, ZF, and ZR-like (Dumontet \& Martinez, 2021). However, in adult and parous female and male laboratory mice, it can be classified as two $(Z G, Z F)$ or three (ZG, oZF, and iZF) (Dumontet \& Martinez, 2021).

The ZG is the source of cells for the inner two zones, fasiculata and reticularis, of the cortex. Mitotane can induce the destruction of glomerulosa cells and cause the losing of fasiculata and reticularis (Lyraki \& Schedl, 2021). On the other hand, by the feedback control, prolonged high level of glucocorticoids causes atrophy of the hypothalamic-pituitary unit and the zonae fasiculata and reticularis. In the histological characters in chronic low-dose DEHP groups with H-E and trichrome staining, showed normal cell shapes and arrangement in the zonas with thickened ZFs, but not change in ECM localizing patterns. DEHP has a function as a modulator of cell proliferation and differentiation in various cells such as T-47D cell, endometrial stromal cell, thyroid cells, etc (Richardson et al., 2018; Crobeddu et al., 2019; Cheon, 2020). It is may cause of the increase of wet weight of adrenal gland. Though the molecular level studies are needed, it is suspected that chronic low-dose DEHP administration could be the cause of the stimulated differentiation of ZG cells to ZF cells.

Adrenal cortex is a steroidogenic tissue but has differences in the expression of $\mathrm{P} 450$ genes from other steroidogenic organs such as testis and ovary. The cytochrome P450 (CYP) genes Cyp51, Cyp11a1, Cyp17a1, Cyp11b1, Cyp11b2, and Cyp21a1 participate in the adrenal production of corticosteroids, glucocorticoids, mineralocorticoids, and adrenal androgen. These steroids are synthesized in zona-specific manners because steroidogenic enzymes are zona-specific expression. Aldosterone (a mineralocorticoid) is secreted by the ZG. Glucocorticoids, cortisol, corticosterone, dehydroepiandrosterone (DHEA), dehydroepiandrosterone sulfate (DHEAS), androgens and estrogens are synthesized in the $\mathrm{ZF}$ and $\mathrm{ZR}$. The expression of these steroids is under the influence of ACTH (Niakan \& McCabe, 2005). In the case of mouse, Cyp17a1 expression does not occur in the adrenal after embryonic development and results in the production of corticosterone and the absence of DHEA and DHEAS (Martinez-Arguelles \& Papadopoulos, 2015) in epigenic modification. Cyp17a1 is express in adrenal gland of Crem knockout mice through epigenetic regulation (Košir et al., 2012). Interestingly, in DEHP1330 group, the CYP17A1 specific staining was detected. It is suggested that the possibility of the epigenic effect of chronic low-dose DEHP 
in adrenal cortex.

Previously a few groups including Martinez-Arguelles \& Papadopoulos (2015) suggested that adrenal cortex is a target of DEHP as in Leydig cells of testis. Exposing to $100 \mathrm{mg} / \mathrm{kg} /$ day DEHP appears to be the threshold for adult endocrine disruption following an in utero exposure. DEHP effects on the adrenal gland as EDC and exerts long-term effects. DEHP decreases the expression of steroidogenic acute regulatory protein (StAR) expression in both mouse and human. It also decreases the levels of $17 \alpha$-hydroxylase (CYP17A1) and cytochrome P450 (Martinez-Arguelles et al., 2009; Kariyazono et al., 2015). Fetal exposure resulted in altered ZG development in a dose- and time-specific manner (Martinez-Arguelles et al., 2011). Interestingly in maternal group, the expression level of CYP11A1 was not affected by chronic low-dose DEHP administration. However, DAX1 expression was dramatically decreased. Put together, it is suggested that adrenal cortex can be a target of chronic low-dose DEHP.

In summary, the cell shapes and arrangement in zonas were not changed by the chronic lowdose DEHP administration but the thickness of ZF was increased. The expression levels of CYP11B1 was not different between groups but not in DAX1. Its expression was decreased by DEHP. In addition, the CYP17A1 specific signaling was detected in ZG of DEHP1330 group. Previously we showed that the administration of DEHP with the strategy of OECD test guideline 443 did not cause of decrease of litter size (Cha et al., 2017). Put together, these results suggest that chronic low-dose DEHP exposing may cause modified structure and function of adrenal cortex to compensation for DEHP disturbance as EDC.

\section{REFERENCES}

Ahmad S, Sharma S, Afjal MA, Habib H, Akhter J, Goswami P, Parvez S, Akhtar M, Raisuddin S (2022) mRNA expression and protein-protein interaction (PPI) network analysis of adrenal steroidogenesis in response to exposure to phthalates in rats. Environ Toxicol Pharmacol 89:103780.

Bloom MS, Whitcomb BW, Chen Z, Ye A, Kannan K, Louis GMB (2015) Associations between urinary phthalate concentrations and semen quality parameters in a general population. Hum Reprod 30:2645-2657.

Cha S, Baek JW, Ji HJ, Choi JH, Kim C, Lee MY, Hwang YJ, Yang E, Lee SH, Jung HI, Cheon YP (2017) Disturbing effects of chronic low-dose 4-nonylphenol exposing on gonadal weight and reproductive outcome over one-generation. Dev Reprod 21:121-130.

Chen X, Xu S, Tan T, Lee ST, Cheng SH, Lee FW, Xu SJL, Ho KC (2014) Toxicity and estrogenic endocrine disrupting activity of phthalates and their mixtures. Int J Environ Res Public Health 11:3156-3168.

Cheon YP (2020) Di-(2-ethylhexyl) phthalate (DEHP) and uterine histological characteristics. Dev Reprod 24:1-17.

Crobeddu B, Ferraris E, Kolasa E, Plante I (2019) Di(2-ethylhexyl) phthalate (DEHP) increases proliferation of epithelial breast cancer cells through progesterone receptor dysregulation. Environ Res 173:165-173.

Dumontet T, Martinez A (2021) Adrenal androgens, adrenarche, and zona reticularis: A human affair? Mol Cell Endocrinol 528:111239.

Gummow BM, Scheys JO, Cancelli VR, Hammer GD (2006) Reciprocal regulation of a glucocorticoid receptor-steroidogenic factor-1 transcription complex on the Dax-1 promoter by glucocorticoids and adrenocorticotropic hormone in the adrenal cortex. Mol Endocrinol 
20:2711-2723.

Ito Y, Kamijima M, Nakajima T (2019) Di(2-ethylhexyl) phthalate-induced toxicity and peroxisome proliferator-activated receptor alpha: A review. Environ Health Prev Med 24:47.

Kariyazono Y, Taura J, Hattori Y, Ishii Y, Narimatsu S, Fujimura M, Takeda T, Yamada H (2015) Effect of in utero exposure to endocrine disruptors on fetal steroidogenesis governed by the pituitary-gonad axis: A study in rats using different ways of administration. J Toxicol Sci 40:909-916.

Kim AC, Reuter AL, Zubair M, Else T, Serecky K, Bingham NC, Lavery GG, Parker KL, Hammer GD (2008) Targeted disruption of $\beta$-catenin in Sf1-expressing cells impairs development and maintenance of the adrenal cortex. Development 135:2593-2602.

Kim CL, Cha SY, Chun MY, Kim B, Choi MY, Cheon YP (2015) Positive effects of diphlorethohydroxycarmalol (DPHC) on the stability of the integument structure in dietinduced obese female mice. Dev Reprod 19:145-152.

Koch HM, Bolt HM, Angerer J (2004) Di(2-ethylhexyl)phthalate (DEHP) metabolites in human urine and serum after a single oral dose of deuterium-labelled DEHP. Arch Toxicol 78:123130.

Komar CM, Braissant O, Wahli W, Curry TE Jr (2001) Expression and localization of PPARs in the rat ovary during follicular development and the periovulatory period. Endocrinology 142:4831-4838.

Košir R, Zmrzljak UP, Bele T, Acimovic J, Perse M, Majdic G, Prehn C, Adamski J, Rozman D (2012) Circadian expression of steroidogenic cytochromes P450 in the mouse adrenal gland - involvement of cAMP-responsive element modulator in epigenetic regulation of Cyp17a1. FEBS J 279:1584-1593.

Li X, Fang EF, Scheibye-Knudsen M, Cui H, Qiu L, Li J, He Y, Huang J, Bohr VA, Ng TB, Guo H (2014) Di-(2-ethylhexyl) phthalate inhibits DNA replication leading to hyperPARylation, SIRT1 attenuation and mitochondrial dysfunction in the testis. Sci Rep 4:6434.

Lorz PM, Towae FK, Enke W, Jäckh R, Bhargava N, Hillesheim W (2012) Ullmann's Encyclopedia of Industrial Chemistry. John Wiley \& Sons, New York, NY.

Lovekamp-Swan T, Davis BJ (2003) Mechanisms of phthalate ester toxicity in the female reproductive system. Environ Health Perspect 111:139-145.

Lyraki R, Schedl A (2021) Adrenal cortex renewal in health and disease. Nat Rev Endocrinol 17:421-434.

Maloney EK, Waxman DJ (1999) trans-Activation of PPAR $\alpha$ and PPAR $\gamma$ by structurally diverse environmental chemicals. Toxicol Appl Pharmacol 161:209-218.

Martinez-Arguelles DB, Culty M, Zirkin BR, Papadopoulos V (2009) In utero exposure to di(2-ethylhexyl) phthalate decreases mineralocorticoid receptor expression in the adult testis. Endocrinology 150:5575-5585.

Martinez-Arguelles DB, Guichard T, Culty M, Zirkin BR, Papadopoulos V (2011) In utero exposure to the antiandrogen di-(2-ethylhexyl) phthalate decreases adrenal aldosterone production in the adult rat. Biol Reprod 85:51-61.

Martinez-Arguelles DB, Papadopoulos V (2015) Mechanisms mediating environmental chemicalinduced endocrine disruption in the adrenal gland. Front Endocrinol 6:29.

Martínez-Razo LD, Martínez-Ibarra A, Vázquez-Martínez ER, Cerbón M (2021) The impact of di-(2-ethylhexyl) phthalate and mono(2-ethylhexyl) phthalate in placental development, function, and pathophysiology. Environ Int 146:106228.

McCabe ERB (2001) Adrenal hypoplasias and aplaisas. In: Scriver CR, Beaudet AL, Sly WS, Valle D, Childs B, Kinzler KW, Vogelstein B (eds), The Metabolic and Molecular Bases of Inherited 
Disease. McGraw-Hill, New York, NY, pp 4263-4274.

Niakan KK, McCabe ERB (2005) DAX1 origin, function, and novel role. Mol Genet Metab 86:70-83.

Ragazzon B, Lefrançois-Martinez AM, Val P, Sahut-Barnola I, Tournaire C, Chambon C, Gachancard-Bouya JL, Begue RJ, Veyssière G, Martinez A (2006) Adrenocorticotropindependent changes in SF-1/DAX-1 ratio influence steroidogenic genes expression in a novel model of glucocorticoid-producing adrenocortical cell lines derived from targeted tumorigenesis. Endocrinology 147:1805-1818.

Richardson KA, Hannon PR, Johnson-Walker YJ, Myint MS, Flaws JA, Nowak RA (2018) Di (2-ethylhexyl) phthalate (DEHP) alters proliferation and uterine gland numbers in the uteri of adult exposed mice. Reprod Toxicol 77:70-79.

Scheys JO, Heaton JH, Hammer GD (2011) Evidence of adrenal failure in aging Dax1-deficient mice. Endocrinology 152:3430-3439.

Simon C, Onghena M, Covaci A, Van Hoeck E, Van Loco J, Vandermarken T, Van Langenhove K, Demaegdt H, Mertens B, Vandermeiren K, Scippo ML, Elskens M (2016) Screening of endocrine activity of compounds migrating from plastic baby bottles using a multi-receptor panel of in vitro bioassays. Toxicol In Vitro 37:121-133.

Turcu AF, Nanba AT, Auchus RJ (2018) The rise, fall, and resurrection of 11-oxygenated androgens in human physiology and disease. Horm Res Paediatr 89:284-291.

Tyl RW, Price CJ, Marr MC, Kimmel CA (1988) Developmental toxicity evaluation of dietary di(2-ethylhexyl)phthalate in Fischer 344 rats and CD-1 mice. Fundam Appl Toxicol 10:395412.

United States Environmental Protection Agency (2013) America's Children and the Environment. 3rd ed. United States Environmental Protection Agency, Washington, DC, p 304.

Vandenberg LN, Hunt PA, Gore AC (2019) Endocrine disruptors and the future of toxicology testing - lessons from CLARITY - BPA. Nat Rev Endocrinol 15:366-374.

Zeiger E, Haworth S, Mortelmans K, Speck W (1985) Mutagenicity testing of di(2-ethylhexyl) phthalate and related chemicals in Salmonella. Environ Mutagen 7:213-232.

Zhang NN, Wang CN, Ni X (2020) Construction of transgenic mice with specific Cre recombinase expression in the zona fasciculata in adrenal cortex. Sheng Li Xue Bao 72:148-156. 